\title{
Fibromiyaljili Hastalarda D Vitamini Düzeyi Hastalık Şiddeti ve Enflamatuar Göstergeler ile İlişkili midir?
}

\author{
Türkan TURGAY ${ }^{1}$, Pınar GÜNEL KARADENİ ${ }^{2}$ \\ 1 SANKO Üniversitesi Tıp Fakültesi, Fiziksel Tıp ve Rehabilitasyon Anabilim Dalı, Gaziantep. \\ 2 SANKO Üniversitesi Tıp Fakültesi, Biyoistatistik Anabilim Dalı, Gaziantep.
}

\section{ÖZET}

Bu çalışmada fibromiyalji hastalarının D vitamini seviyeleri ile hastalık şiddeti ve enflamasyonla ilişkisini nötrofil lenfosit oranı (N/L), platelet lenfosit oranı $(\mathrm{P} / \mathrm{L})$, ortalama trombosit hacmi $(\mathrm{OTH})$, eritrosit sedimentasyon hızı $(\mathrm{ESH})$ ve C-reaktif protein (CRP) parametrelerini kullanarak değerlendirme ve klinik önemini araștırma amaçlanmıștır. Calıșmaya SANKO Üniversitesi Uygulama ve Araștırma Hastanesi Fizik Tedavi ve Rehabilitasyon Polikliniğine başvurmuş fibromiyaljili hastalar ve sağlıklı kontroller dahil edildi. Fibromiyalji hastalarının fonksiyonel durumunu değerlendirmek için Fibromiyalji Etki Anketi kullanıldı. Hastalara ait demografik ve laboratuvar bilgileri retrospektif olarak dosya taraması ile elde edildi. Fibromiyalji $(n=51)$ ve kontrol $(n=46)$ grubu arasında cinsiyet ve yaş bakımından istatistiksel olarak anlamlı bir fark yoktu (sırasıyla; $\mathrm{p}=1.000, \mathrm{p}=0.074$ ). Hasta ve kontrol gruplarının trombosit, $\mathrm{OTH}$, nötrofil, lenfosit, $\mathrm{N} / \mathrm{L}, \mathrm{P} / \mathrm{L}$ değerleri arasında istatistiksel olarak anlamlı bir fark bulunamadı ( $>>0.05)$. Fibromiyalji hastalarında D vitamini eksikliği, CRP ve ESH düzeylerindeki yükseklik istatistiksel olarak anlamlı bulunurken (sırasıyla $\mathrm{p}<0.001, \mathrm{p}=0.009, \mathrm{p}=0.036$ ), D vitamini eksikliği ve hastalık şiddeti arasında anlamlı bir korelasyon bulunamadı $(\mathrm{p}=0.313)$. Her iki grupta $\mathrm{D}$ vitamini ve hastalık şiddeti ile diğer parametreler arasında da istatistiksel olarak anlamlı bir korelasyon saptanmamıştır ( $\mathrm{p}>0.05)$. Çalışmamız her iki grupta D vitamini eksikliğinin hastalık şiddeti ve trombosit, OTH, N/L, P/L, ESH, CRP değerleri arasında anlamlı bir ilişki olmadığını ortaya koydu. Fibromiyalji sendromunda D vitamini ile enflamasyon belirteçlerinin ve hastalık şiddetinin arasındaki ilişkiyi değerlendirmek için daha geniş çaplı çalışmalara ihtiyaç vardır.

Anahtar Sözcükler: Fibromiyalji. D vitamini. Enflamasyon.

Is Vitamin D Level Related to Disease Severity and Inflammatory Indicators in Patients with Fibromyalgia

\begin{abstract}
In this study, it is aimed to evaluate the relationship between vitamin D levels and disease severity and inflammation parameters using neutrophil lymphocyte ratio (N/L), platelet lymphocyte ratio (P/L), mean platelet volume (MPV), erythrocyte sedimentation rate (ESR) and Creactive protein (CRP) in fibromyalgia patients and to examine the clinical significance of it. Patients with fibromyalgia and healthy controls who applied to SANKO University Research and Application Hospital Physical Therapy and Rehabilitation Outpatient Clinic were included. The Fibromyalgia Impact Questionnaire was used to evaluate the functional status of patients with fibromyalgia. The demographic and laboratory data of the patients were retrospectively obtained. There was no statistically significant difference in age $(p=1.000, p=0.074)$ and in gender fibromyalgia $(n=51)$ and controls $(n=46)$. There was no statistically significant difference between patients with fibromyalgia and healthy controls in platelet, MPV, neutrophil, lymphocyte, N/L, P/L values ( $p>0.05)$. Vitamin D deficiency and high CRP and ESR levels was statistically significant in fibromyalgia patients $(p<0.001, p=0.009, p=0.036$, respectively), but no significant correlation was found between vitamin $\mathrm{D}$ and disease severity $(\mathrm{p}=0.313$ ). There was no statistically significant correlation between vitamin $\mathrm{D}$ with other parameters in both groups ( $>0.05$ ). There was no significant relationship between vitamin D deficiency and disease severity and platelet, MPV, N/L, P/L, ESR, CRP values of in both groups. Larger studies are needed to evaluate the relationship between vitamin D and inflammation markers and disease severity in fibromyalgia syndrome.
\end{abstract}

Key Words: Fibromyalgia. Vitamin D. Inflammation.

Geliş Tarihi: 11 Eylül 2019

Kabul Tarihi: 05 Aralık 2019

Dr. Türkan TURGAY

SANKO Üniversitesi Tıp Fakültesi,

Fiziksel Tıp ve Rehabilitasyon Anabilim Dalı, Gaziantep.

Tel.: 05366807134

E-posta: TTurgay@sankotip.com
Fibromiyalji sendromu (FMS) eklem tutukluluğu, ağrılı hassas noktalar ve yaygın ağrı ile karakterize kronik sistemik bir hastalıktır. Sik rastlanan diğer semptomlar uyku bozukluğu, yorgunluk, kognitif disfonksiyon, parestezi ve anksiyetedir ${ }^{1-3}$. FMS prevalansının tüm dünyada $\% 0.2-6.6$ olduğu ve hastalığın, kadınları \% 2.4 - 6.8 gibi yüksek bir prevalans ile daha sık etkilediği gösterilmiştir ${ }^{4}$. Fibromiyaljide etiyoloji ve patogenez halen tam olarak anlaşılamamıştır. FMS'nin oluşmasına katkıda bulunan birçok mekanizma olduğu düşünülmektedir. Hastalıkta rol oynadı- 
ğ1 düşünülen santral ve otonom sinir sitemi, immün sistem, sitokin, nörotransmitter ve hormonların disfonksiyonuna ait birçok kanıt bulunmuştur ${ }^{5,6}$.

D vitamininin kalsiyum ve fosfor metabolizmasında ve kemik homeostazında önemli rol oynadığı bilinmektedir. Bununla birlikte immün sistem, beyin, gözler, pankreas, kalp, yağ dokusu, tiroid, paratiroid gibi birçok doku ve organda $\mathrm{D}$ vitamini reseptörü gösterilmiş ve $\mathrm{D}$ vitamini eksikliğinin immün yanıtın düzenlenmesinde, otoimmün hastalıklarda, enfeksiyöz hastalıklarda, çeşitli kanserlerde, kardiyovasküler ve metabolik hastalıklarda da önemli rol oynadığ $\breve{1}_{1}$ ileri sürülmüștür ${ }^{7-9}$. D vitamininin ağrı ile ilişkilendirildiği çalışmalarda fibromiyaljide de önemli rol oynadığ gösterilmiştir ${ }^{10,11}$. Ancak literatürde fibromiyalji ve D vitamini düzeyleri arasındaki ilişki hakkında tartışmalı sonuçlar da bulunmaktadır ${ }^{12}$.

C-reaktif protein (CRP) akut enfeksiyon ve enflamasyonu gösteren birçok romatolojik hastalık için tanısal önem taşıyan proinflamatuar bir parametre olarak kabul edilir ${ }^{13}$. Nötrofil lenfosit oranı $(\mathrm{N} / \mathrm{L})$ ve platelet lenfosit oranı $(\mathrm{P} / \mathrm{L})$ sistemik enflamatuar hastalıkların prognozuyla korelasyon gösteren ucuz ve kolay hesaplanabilir bir yöntemdir ${ }^{14,15}$. Ortalama trombosit hacmi (OTH), trombosit fonksiyon ve aktivitesinin göstergesi olup enflamasyon ve trombüs kaskadı ilişkili bir parametredir ${ }^{16}$. FMS hastalarında trombosit, nötrofil sayısı, ESH ve CRP seviyelerinin sağlıkl bireyler için kabul edilen normal değerler arasında olması beklenir ${ }^{17}$. Ancak bu değerler normal bireyler için kabul edilen değerler arasında olsa bile fibromiyalji hastaları ve kontrol grupları arasında yapılan karşılaştırmalar ile farklılıklar olabilir.

$\mathrm{Bu}$ çalışmada fibromiyalji hastalarının $\mathrm{D}$ vitamini seviyeleri ile hastalık şiddeti ve enflamasyonla ilişkisini nötrofil lenfosit oranı $(\mathrm{N} / \mathrm{L})$, platelet lenfosit oranı $(\mathrm{P} / \mathrm{L})$, ortalama trombosit hacmi $(\mathrm{OTH})$, eritrosit sedimentasyon hizı (ESH) ve C-reaktif protein (CRP) parametrelerini kullanarak değerlendirme ve bu parametrelerin fibromiyaljinin patogenezi ve tedavisindeki potansiyel rolünü araștırma amaçlanmıştır.

\section{Gereç ve Yöntem}

$\mathrm{Bu}$ çalışmaya SANKO Üniversitesi Uygulama ve Araştırma Hastanesi Fizik Tedavi ve Rehabilitasyon Polikliniğine 2018 Ağustos - 2019 Ocak tarihlerinde başvurmuş fibromiyaljili hastalar ve sağlıklı kontroller dahil edildi. Çalışmaya başlamadan önce SANKO Üniversitesi Klinik Araştırmalar Etik Kurulundan onay alındı (Karar No: 2019/04-04; Tarih: 08 Nisan 2019).

Hastanemizde dosya taraması ile en az 3 aydır düzenli takiplere gelen ve hasta yakınmalarını ön plana çıkaran Amerikan Collage of Rheumatology (ACR) 2010 tanı kriterlerine ${ }^{18}$ göre fibromiyalji tanısı almış 51 hasta ve 46 sağlıklı kontrol çalışmaya dahil edildi. Endokrinolojik, romatolojik, enfeksiyöz, nörolojik, psikiyatrik hastalığı olanlar ile malignite ve travma öyküsü olan hastalar çalışma dışında bırakıldı. Fibromiyalji semptomları olmayan, hastanemizde rutin laboratuvar incelemesi yapılan yaş ve cinsiyet uyumlu bireyler sağlıklı kontrol grubu olarak alındı. Hastalara ait demografik ve rutin laboratuvar bilgileri retrospektif olarak dosya taraması ile elde edildi (Tablo I). Olguların ve sağlıklı kontrollerin yaş, cinsiyet, 25(OH) D3 vitamini $(\mathrm{ng} / \mathrm{ml})$, trombosit $\left(\mathrm{K} / \mathrm{mm}^{3}\right)$, OTH (fL), nötrofil $\left(\mathrm{K} / \mathrm{mm}^{3}\right)$, lenfosit $\left(\mathrm{K} / \mathrm{mm}^{3}\right), \mathrm{P} / \mathrm{L}$, $\mathrm{N} / \mathrm{L}, \mathrm{ESH}(\mathrm{ml} / \mathrm{h})$, CRP (mg/l) gibi parametreleri kaydedildi. Hastaların fonksiyonel durumunu ve progresyonunu değerlendirmek için takipte kullanılan Fibromiyalji Etki Anketi'nin Türkçe versiyonu (FEA) ${ }^{19}$ kullanıldı. FEA fonksiyonel durum, genel durum ve semptomlar olmak üzere üç bölümden oluşan toplam 21 soru ile hastalarda oluşan limitasyonları ve fonksiyonel dizabiliteyi değerlendiren bir ankettir. Bütün sorular 0-10 arasında numerik skala ile değerlendirilmektedir. Yüksek skorlar düşük fonksiyonellik düzeyini göstermektedir.

Veriler IBM SPSS Statistics 23 programı ile analiz edildi. Tanımlayıcı istatistik olarak; sürekli değişkenler için ortalama ve standart sapma veya medyan ve minimum-maksimum değerleri, nitel değişkenler için frekans ve yüzde değerleri verildi. Grup karşılaştırmalarında; sürekli değişkenler için parametrik test koşullarının sağlanması durumunda bağımsız gruplar t-testi, parametrik test koşullarının sağlanmadığı durumlarda Mann-Whitney U testi kullanıldı. Nitel değişkenlerin grup karşılaştırmaları için ki-kare testi kullanıldı. Sürekli değişkenler arasındaki ilişki Pearson korelasyon katsayısı ile değerlendirildi. İstatistiksel analizlerde $\mathrm{p}<0.05$ olması anlamlı kabul edildi.

\section{Bulgular}

Çalışmaya dahil edilen 51 fibromiyaljili (46 (\%90.1) kadın, 5 (\%9.8) erkek) ve 46 sağlıklı kontrol (46 (\%89.0) kadın, 5 (\%11.0) erkek) arasında yaş bakımindan istatistiksel anlamlılı yoktu (sırasıyla; $\mathrm{p}=1.000, \mathrm{p}=0.074$ ). Hasta ve kontrol gruplarının trombosit, OTH, nötrofil, lenfosit, N/L, P/L değerleri arasinda anlamlı bir fark yoktu (Tablo I). Fibromiyalji hastalarında D vitamini eksikliği ile CRP ve ESH düzeylerindeki yükseklik anlamlı bulundu (sırasıyla $\mathrm{p}<0.001, \mathrm{p}=0.009, \mathrm{p}=0.036$ ) (Tablo I). Hem hasta grupta hem de kontrol grubunda $\mathrm{D}$ vitamini ile diğer parametreler arasında da istatistiksel olarak anlamlı bir korelasyon saptanmadı (Tablo II). D vitamini ve hastalık şiddeti arasında anlamlı bir korelasyon bulunamadi $(p=0.313)$. Ayrıca fibromiyalji hastalarında, hastalığın şiddeti ile yalnızca trombosit sayısı arasında anlamlı bir ilişki vardı ancak korelasyon katsayısı çok düşük elde edildi (Tablo III). 
Fibromiyaljide D Vitamini ve Enflamasyon İlişkisi

Tablo I. Hasta ve kontrol grubu karşılaştırmaları

\begin{tabular}{|l|c|r|c|}
\hline & Hasta & Kontrol & $p$ \\
\hline $\begin{array}{l}\text { Cinsiyet } \\
\text { Erkek n (\%) } \\
\text { Kadın n (\%) }\end{array}$ & $\begin{array}{r}5(\% 10) \\
46(\% 90)\end{array}$ & $\begin{array}{r}5(\% 11) \\
41(\% 89)\end{array}$ & $1.000^{\mathrm{a}}$ \\
\hline Yaş & $39.10 \pm 11.10$ & $43.04 \pm 10.35$ & $0.074^{\mathrm{b}}$ \\
\hline D vitamini & $12.0(2.8-38.0)$ & $22.6(2.7-52.0)$ & $<0.001^{\mathrm{c}}$ \\
\hline ESH & $16.0(3.0-56.0)$ & $13.0(1.0-34.0)$ & $0.036^{c}$ \\
\hline CRP & $3.23(3.02-71.20)$ & $3.23(3.00-13.30)$ & $0.009^{c}$ \\
\hline N & $3.96(2.39-8.57)$ & $3.98(2.28-5.97)$ & $0.285^{c}$ \\
\hline L & $2.08(1.37-4.82)$ & $2.26(1.38-3.28)$ & $0.549^{c}$ \\
\hline N/L & $1.81(1.00-3.59)$ & $1.75(0.99-3.67)$ & $0.207^{c}$ \\
\hline Trombosit & $265.38 \pm 70.09$ & $267.89 \pm 54.59$ & $0.846^{\mathrm{b}}$ \\
\hline OTH & $7.69 \pm 1.32$ & $7.51 \pm 1.13$ & $0.470^{\mathrm{b}}$ \\
\hline P/L & $120.99 \pm 39.76$ & $122.93 \pm 38.00$ & $0.807^{\mathrm{b}}$ \\
\hline
\end{tabular}

N: Nötrofil, L: Lenfosit, N/L: Nötrofil lenfosit oran1, P/L: Platelet lenfosit oran1, OTH: Ortalama Trombosit Hacmi, ESH: Eritrosit Sedimentasyon Hızı, CRP: C reaktif protein

${ }^{\mathrm{a}} \mathrm{Ki}$-kare testi, ${ }^{\mathrm{b}}$ Bağımsız gruplar t-testi, ${ }^{\mathrm{C}}$ Mann-Whitney U testi

\section{Tartışma}

Fibromiyalji sendromunda D vitamini ve hastalık şiddeti ile enflamatuar parametreler arasındaki ilişkiyi araştırdığımız bu çalışmada fibromiyalji hastalarında kontrollere göre D vitaminin daha düşük ve CRP değerlerinin daha yüksek olduğu görüldü. Her ne kadar $\mathrm{D}$ vitamini eksikliği ve enflamasyon düzeyi arasındaki ilişki birçok hastalıkta belirtilmiş olsa da, çalışmamızda fibromiyalji hastalarında bu tür bir ilişki açıklanamamıştır.

D vitamini, kemik sağlığı ve kalsiyum/fosfat metabolizmasında iyi tanımlanmış bir rolü olan yağda çözünebilen bir hormondur. Son yapılan çalışmalar D vitaminini diğer fizyolojik fonksiyonlar ve patolojik durumlarla ilişkilendirmiştir. Artrit, kas ağrısı ve fibromiyalji gibi kronik yaygın ağrılı hastalarda, artrit olmayanlara göre anlamlı derecede düşük bir $25(\mathrm{OH})$ vitamin D3 konsantrasyonu olduğunu göstermekte$\operatorname{dir}^{20,21}$. Bununla birlikte düşük $25(\mathrm{OH})$ vitamin D3 konsantrasyonlarının multiple skleroz ${ }^{22}$, romatoid artrit $^{23}$, sistemik lupus eritrematozis ${ }^{24}$ gibi enflamatuar hastalıklar ile de ilişkili olabileceğini gösteren çalışmalar da mevcuttur. Bizim çalışmamızda da benzer şekilde fibromiyaljili hastalarda kontrol grubuna k1yasla $25(\mathrm{OH})$ vitamin D3 seviyeleri daha düşük bulunmuştur.

Fibromiyalji, enflamatuar bir hastalık olarak tanımlanmamaktadır. Son zamanlarda yapılan çalışmalar

Tablo II. Fibromiyalji hastalarında ve kontrol grubunda D vitamini ve diğer parametreler arasındaki ilişki

\begin{tabular}{|c|c|c|c|c|c|c|c|c|c|c|c|}
\hline & & & ESH & CRP & $\mathrm{N}$ & L & $\mathrm{N} / \mathrm{L}$ & Trombosit & ОТН & PIL & FEA \\
\hline \multirow{4}{*}{ 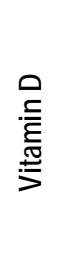 } & \multirow{2}{*}{ 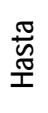 } & $r$ & 0.027 & -0.197 & 0.052 & 0.188 & -0.178 & 0.223 & -0.192 & -0.004 & 0.144 \\
\hline & & $p$ & 0.851 & 0.167 & 0.717 & 0.186 & 0.210 & 0.116 & 0.176 & 0.976 & 0.313 \\
\hline & \multirow{2}{*}{$\begin{array}{l}\overline{0} \\
\text { 을 } \\
\text { ․ }\end{array}$} & $r$ & -0.169 & -0.122 & -0.115 & 0.123 & -0.152 & -0.238 & 0.077 & -0.193 & - \\
\hline & & $p$ & 0.262 & 0.420 & 0.447 & 0.415 & 0.313 & 0.111 & 0.609 & 0.199 & - \\
\hline
\end{tabular}

FEA: Fibromiyalji Etki Anketi, N: Nötrofil, L: Lenfosit, N/L: Nötrofil lenfosit oran1, P/L: Platelet lenfosit oran1, OTH: Ortalama Trombosit Hacmi, ESH: Eritrosit Sedimentasyon Hızı, CRP: C reaktif protein

Tablo III. Fibromiyalji hastalarında, hastalığın fonksiyonel durumu ile diğer parametreler arasındaki ilişki

\begin{tabular}{|c|c|c|c|c|c|c|c|c|c|}
\hline & & ESH & CRP & $\mathrm{N}$ & L & $N / L$ & Trombosit & ОTH & P/L \\
\hline \multirow{2}{*}{ 出 } & $r$ & 0.091 & -0.110 & 0.079 & 0.163 & 0.011 & 0.304 & -0.021 & 0.208 \\
\hline & $p$ & 0.524 & 0.440 & 0.580 & 0.253 & 0.940 & 0.030 & 0.884 & 0.143 \\
\hline
\end{tabular}

FEA: Fibromiyalji Etki Anketi, N: Nötrofil, L: Lenfosit, N/L: Nötrofil lenfosit oranı, P/L: Platelet lenfosit oranı, OTH: Ortalama Trombosit Hacmi, ESH: Eritrosit Sedimentasyon Hızı, CRP: C reaktif protein 
sitokinleri, enflamatuar belirleyicileri, uyku bozukluklarını, hiperaljezi, bilişsel işlev bozukluğunu, serum leptin seviyelerini ve diğer enflamatuar göstergeleri FMS için potansiyel belirteçler olarak tanımlamıştır ${ }^{25-}$ 27. Hastalığın semptom şiddetini ve progresyonunu gösteren güvenilir laboratuvar belirteçleri bulunmamaktadir.

Sistemik inflamasyonda dolaşımdaki lenfosit sayısında azalma, nötrofili ve trombositoz meydana gelir. Nötrofil lenfosit oranı (N/L) ve platelet lenfosit oran $(\mathrm{P} / \mathrm{L})$ sistemik enflamatuar yanıtı belirlemek için prognostik faktör olarak önerilen enflamatuar parametreler olarak değerlendirilmektedir. N/L; diabetes mellitus, koroner arter hastalığ 1 , ülseratif kolit ve inflamatuar artrit gibi sistemik veya lokal enflamatuar yanıtla karakterize bazı patolojilerin tanısında oldukça önemlidir ${ }^{28}$. Trombosit aktivasyonunun bir belirleyicisi olan ortalama trombosit hacmi (OTH), kardiyovasküler hastalık için bağımsız bir risk faktörü olarak kabul edilmektedir. Fibromiyaljili hastalarda Haliloğlu ve ark. yaptığı bir çalışma OTH değerinin; benzer şekilde Aktürk ve ark. yaptığı bir çalışma ise N/L and OTH değerlerinin yüksek olduğunu göstermiştir ${ }^{29,} 30$. Ancak fibromiyaljinin non-enflamatuar romatizmal bir durum olduğunu gösteren çalışmalar da mevcuttur ${ }^{31}$. Bizim çalışmamızda fibromiyalji hastalarında romatizmal ya da otoimmün hastalık bulunmamaktaydı. Hasta ve kontrol grupları arasında enflamatuar parametrelerden $\mathrm{N} / \mathrm{L}, \mathrm{P} / \mathrm{L}$, trombosit ve $\mathrm{OTH}$ arasında anlamlı bir fark izlenmemiştir.

Çalışmamızdaki veriler fibromiyalji hastalarında enflamasyonun karakteristik belirteçlerinden CRP ve ESH seviyelerinin kontrol grubuna göre daha yüksek olduğunu göstermiştir. CRP yüksekliği genel enflamasyonu gösterir ve fibromiyalji hastalarındaki bu durum CRP yüksekliğinin zaman içinde hem semptomlara hem de biyolojik belirteçlere yön veren biyodavranışsal bir kofaktör olması yönünde yorumlanabi$\operatorname{lir}^{25}$. Bununla birlikte FMS hastalarında egzersizin CRP düzeylerini azaltarak hastalarda anti-enflamatuar etki gösterdiğine dair çalışmalar da mevcuttur ${ }^{32}$. Her ne kadar son yıllarda yapılan çalışmalar fibromiyaljide enflamatuar yanıt sisteminin varlığının klinik semptomlar ve biyokimyasal veriler arasında paralellik olduğunu vurgulayan belirli sitokin (IL-6, IL-8) seviyelerinde yükseklik olduğunu ileri sürmüş olsa da ${ }^{33,34}$, CRP ve ESH böyle bir ilişki tam olarak bildirilmemiştir.

Bu makalenin amacı, daha önceki çalışmalardan farklı olarak fibromiyaljide D vitamini eksikliğinin enflamasyon ile arasındaki ilişkisi ve hastalığın patogenezi ve tedavisindeki potansiyel rolü hakkında bilgi edinmekti. Fibromiyaljide enflamasyon belirtileri hastalara verilen tedaviler için farklı terapötik stratejilere yol açabilir. Ancak çalışmamızın sonuçları, fibromiyaljide umut verici enflamatuar belirteçler olarak gösterilen N/L, P/L, trombosit, OTH, CRP ve ESH parametrele- rin D vitamini eksikliği ile korele olmadığını göstermiştir. Çalışmamızın bazı kısıtlılıkları mevcuttur. Bunlardan ilki hasta ve kontrol grubundaki katılımc1 sayısının az olmasıdır. İkincisi, retrospektif bir analizin hastalarımızda egzersize cevap ile CRP düzeylerini değerlendirmemize imkan vermemesidir.

Sonuç olarak FMS hastalarında vitamin D ve hastalık dizabilitesinin enflamatuar parametreler ile değerlendirilmesi basit, pahalı olmayan bir yöntem olarak görülse de bu konuda daha fazla hasta sayısı ve klinik değerlendirme parametreleri ile yapılacak çalışmalara gereksinim vardır.

\section{Kaynaklar}

1. Clauw DJ. Fibromyalgia: an overview. Am J Med 2009;122(12):3-13.

2. Bellato E, Marini E, Castoldi F et al. Fibromyalgia syndrome: etiology, pathogenesis, diagnosis, and treatment. Pain Res Treat. 2012:11;426130.

3. Smith HS, Harris R, Clauw D. Fibromyalgia: an afferent processing disorder leading to a complex pain generalized syndrome. Pain Physician. 2011;14(2):217-245.

4. Marques AP, Santo ASDE, Berssaneti AA, Matsutani LA, Yuan SLK. Prevalence of fibromyalgia: literature review update. Rev Bras Reumatol Engl Ed. 2017;7-8;57(4):356-363.

5. Xiao Y, Haynes WL, Michalek JE, Russell IJ. Elevated serum high-sensitivity C-reactive protein levels in fibromyalgia syndrome patients correlate with body mass index, interleukin-6, interleukin-8, erythrocyte sedimentation rate. Rheumatol Int 2013;33(5):1259-1264.

6. Russell IJ, Larson AA. Neurophysiopathogenesis of fibromyalgia syndrome: a unified hypothesis. Rheum Dis Clin N Am. 2009;35:421-435.

7. Masuko K. The multifaceted effects of vitamin D and its potential contribution to rheumatoid arthritis. British Journal of Medicine and Medical Research 2014;4(8): 1680-1690.

8. Cantorna MT, Zhu Y, Froicu M, Wittke A. Vitamin D status, 1,25-dihydroxyvitamin D3, and the immune system. The American Journal of Clinical Nutrition. 2004; 80(6):1717-1720.

9. Body JJ, Bergmann P, Boonen S, Devogelaer JP, Gielen E, Goemaere S, et al. Extraskeletal benefits and risks of calcium, vitamin D and anti-osteoporosis medications. Osteoporosis International. 2012;23(1):1-23.

10. Matthana MH. The relation between vitamin D deficiency and fibromyalgia syndrome in women. Saudi Medical Journal. 2011;32(9):925-929.

11. Olama SM, Senna MK, Elarman MM, Elhawary G. Serum vitamin D level and bone mineral density in premenopausal Egyptian women with fibromyalgia. Rheumatology International 2013;33(1):185-192.

12. Okumus M, Koybası M, Tuncay F, Ceceli E, Ayhan F, Yorgancioglu R, Borman P. Fibromyalgia syndrome: is it related to vitamin D deficiency in premenopausal female patients? Pain Manag Nurs. 2013 Dec;14(4):156-163.

13. Pepys MB, Hirschfield GM. C-reactive protein: a critical update. J Clin Invest. 2003;111(12):1805-12.

14. Bath PM, Butterworth RJ. Platelet size: measurement, physiology and vascular disease. Blood Coagul Fibrinolysis 1996;7:157-161.

15. Akbas EM, Gungor A, Ozcicek A, Akbas N, Askin S, Polat M. Vitamin D and inflammation: evaluation with neutrophil-to- 


\section{Fibromiyaljide D Vitamini ve Enflamasyon İlişkisi}

lymphocyte ratio and platelet-to-lymphocyte ratio. Arch Med Sci. 2016 Aug 1;12(4):721-7.

16. Briggs C. Quality counts: new parameters in blood cell counting. Int J Lab Hematol. 2009;31:277-297.

17. D.J. Clauw. Fibromyalgia. JAMA, 2014;311: 1547.

18. Frederick Wolfe,Danıel J. Clauw, Mary-Ann Fitzcharles, Don L. Goldenberg, Robert S. Katz, Phılıp Mease, Anthony S. Russell,I. Jon Russell, John B. Winfield, Muhammad B. Yunus. The American College of Rheumatology Preliminary Diagnostic Criteria for Fibromyalgia and Measurement of Symptom Severity. Arthritis Care \& Research. 2010;62(5):600-610.

19. Ediz L, Hiz O, Toprak M, Tekeoglu I, Ercan S. The validity and reliability of the Turkish version of the Revised Fibromyalgia Impact Questionnaire. Clin Rheumatol. 2011;30(3):339-46.

20. Wu Z, Malihi Z, Stewart AW, Lawes CM, Scragg R. The association between vitamin $\mathrm{D}$ concentration and pain: a systematic review and meta-analysis. Public Health Nutr. 2018 Aug;21(11):2022-2037.

21. Yilmaz R, Salli A, Cingoz HT, Kucuksen S, Ugurlu H. Efficacy of vitamin D replacement therapy on patients with chronic nonspecific widespread musculoskeletal pain with vitamin D deficiency. Int J Rheum Dis. 2016 Dec;19(12):1255-1262.

22. Voo VTF, O'Brien T, Butzkueven H, Monif M.The role of vitamin D and P2X7R in multiple sclerosis. J Neuroimmunol. 2019 May 15;330:159-169.

23. Bellan M, Sainaghi PP, Pirisi M. Role of Vitamin D in Rheumatoid Arthritis. Adv Exp Med Biol. 2017;996:155-168.

24. Hassanalilou T, Khalili L, Ghavamzadeh S, Shokri A, Payahoo L, Bishak YK. Role of vitamin D deficiency in systemic lupus erythematosus incidence and aggravation. Auto Immun Highlights. 2017 Dec 26;9(1):1.
25. Metyas S, Rezk T, Arkfeld D, Leptich T. Autoinflammation and immunomodulation in inflammatory fibromyalgia syndrome- a review. Curr Rheumatol Rev. 2017;13:98-102.

26. Littlejohn G, Guymer E. Neurogenic inflammation in fibromyalgia. Semin Immunopathol. 2018;40:291-300.

27. Malhotra D, Saxena AK, Dar SA, Kumar V, Nasare N, Tripathi AK et al. Evaluation of cytokine levels in fibromyalgia syndrome patients and its relationship to the severity of chronic pain. J Musculoskelet Pain. 2012;20:164-169.

28. Zahorec R. Ratio of neutrophil to lymphocyte counts-rapid and simple parameter of systemic inflammation and stress in critically ill. Bratisl Lek Listy. 2001;102:5-14.

29. Haliloğlu S, Carlioglu A, Sahiner E, Karaaslan Y, Kosar A. Mean platelet volume in patients with fibromyalgia. Z Rheumatol. 2014 Oct;73(8):742-5.

30. Aktürk S, Büyükavcı R. Evaluation of blood neutrophillymphocyte ratio and platelet distribution width as inflammatory markers in patients with fibromyalgia. Clin Rheumatol. 2017 Aug;36(8):1885-1889.

31. Boyraz I, Karakoyun A, Koç B. Fibromiyalji Sendromunda Enflamasyon Varlığının Nötrofil/Lenfosit ve Platelet/Lenfosit Oranlariyla Saptanmasi. Eur J Health Sci. 2015;1(1):15-19.

32. Ortega E, García JJ, Bote ME, Martín-Cordero L, Escalante Y, Saavedra JM, Northoff H, Giraldo E. Exercise in fibromyalgia and related inflammatory disorders: known effects and unknown chances. Exerc Immunol Rev. 2009;15:42-65.

33. Mendieta D, De la Cruz-Aguilera DL, Barrera-Villalpando MI, Becerril-Villanueva E, Arreola R, Hernández-Ferreira E et al. IL-8 and IL-6 primarily mediate the inflammatory response in fibromyalgia patients. J Neuroimmunol. 2016 Jan 15;290:22-5.

34. Bazzichi L, Rossi A, Massimetti G, Giannaccini G, Giuliano T, De Feo $\mathrm{F}$ et al. Cytokine patterns in fibromyalgia and their correlation with clinical manifestations. Clin Exp Rheumatol. 2007 Mar-Apr;25(2):225-30. 
